\title{
Decision Making Practices In Universities Of Pakistan
}

\author{
Anwar, M. Nadeem, University of Sargodha, Pakistan \\ Yousuf, M. Imran, Pir Mehr Ali Shah Arid Agriculture University, Pakistan \\ Sarwar M., University of Sargodha, Pakistan
}

\begin{abstract}
Decision making can be regarded as an outcome of mental processes (cognitive process) leading to the selection of a course of action among several alternatives. Every decision making process produces a final choice. The output can be an action or an opinion. The purpose of this descriptive survey was to explore the Decision making practices in administrative and academic matters in the universities of Pakistan. A sample of nineteen universities was selected by applying stratified random sampling technique. The respondents, i-e members of university bodies; teachers and administrative officers were selected randomly. Three questionnaires constructed on Likert's fivepoint scale were used for data collection. Data was tabulated and analyzed by using the F-ratio and Chi-square. The survey results revealed that overall decision-making practices in the universities were found unsatisfactory and, most of the decisions were made without application of management decision-making techniques.
\end{abstract}

Keywords: Decision-making practices; participation in Decision-making; University Bodies; Universities of Pakistan

\section{INTRODUCTION}



dministrative sciences grouped three basic roles performed by managers in any organization as interpersonal, informational and decisional. Griffin (2000) includes the managerial roles as technical, interpersonal, conceptual, diagnostic, communication, decision-making, and timemanagement. All these roles are closely interrelated; however the important one is the decisional role. Simon (1976) had described decision making as the "heart of executive activity. It is considered that the prime job that lies at the heart of management and the basis of success depends largely on decision-making. (Marvin, 1981; Jennings and Wattam, 1994 and Choudury, 2001).

There is a general dictionary agreement that a decision concludes and terminates a process. McGrtath (1986) has shown the flow of decision-making process as follows:

Define-----------Options ------------Decide---------Action --------Checkup

Decisions arise out of many different conditions, some decisions are prompted by the performance of daily routine work, some come from the need to change or make more effective the objectives or strategies, other decisions may be generated by unexpected occurrences.

Decision making is not simple, it encompasses with technical aspects in the concerned administrative, organizational development, and the behavioral science have provided qualitative patterns and knowledge, including creative problem-solving, team building, force-field analysis, nominal group technique, brainstorming, goal-setting, management by objectives, theory " $\mathrm{X}$ " and "Y", check lists, analysis of participatory management, job evaluation, empowerment, and management information system (MIS). On the other hand, management science, statistics, and quantitative disciplines have also supplied quantitative methodologies, including network analysis (program 
evaluation review technique, critical path method), forecasting (regression, path analysis, time series), cost-benefit analysis, optimization (linear programming, assignment, transportation), sensitivity analysis, significance testing, simulation, benchmarking, and total quality management (TQM). Moreover, decision support systems and computers based on these programmed techniques are increasingly being used for making better decisions.

Educational administrators may enhance decision-making capabilities by learning more about both qualitative and quantitative techniques, and understanding their contributions to the decision-making process. An administrator who is knowledgeable about decision-making procedures is in a much better position to compare and evaluate the qualitative and quantitative sources of information and, ultimately, to combine alternatives to make the best possible decisions. Behavioral methods and quantitative techniques in organizations are closely related, and when applied to problems they are essentially productivity tools (Foxley, 1980). It is the underlying premise of this study that the uses of managerial techniques are of vital importance for a sound and effective decision-making process.

At present the practice of educational administration and management has changed in response to historical conditions and theoretic developments. The main purpose of administration and management is to help achieving the objectives of an institution. Unless administration or management of education is improved or it is geared to the new needs, changes and challenges, the system or organization cannot secure the desired results or reach the target (Mohanty, 1998). However, Rourke and Brooks (1966) argue that the university administration is highly reluctant to accept any change in the operation of the university. Administrative officers themselves often find it difficult to accept departure from the traditional way of doing things and making decisions.

Governance of higher education involves the authority to make decisions about fundamental policies and practices in several critical areas concerning universities. These areas stretch from their number and location, their mission, their enrolment size, access of students to their instructional programmes and access of the public to other auxiliary services on offer. Other issues of concern include degree requirements; standards expected in student performance, the quality of research and public service activities, the freedom available to individual faculty members in their instructional and research efforts, the appointment of staff, internal organizational structure, allocation of available resources to operating and support programmes.

The dilemma is therefore the location of authority to resolve, manage and control these issues/contentions. This study is all about administrative and academic governance management of campus affairs. It focuses on managerial decision-making techniques and practices in management of higher education in Pakistan.

Pakistan is a developing country and its educational system is facing many problems. The educational system may try to achieve maximum internal efficiency through the effective management, adequate allocations, and optimal use of available resources for improving the quality of education. The situation of education sector particularly educational administration in Pakistan is open to question.

Universities are a place where knowledge and skills are transferred to young generation and ultimately produce better, responsible and productive citizens. Smooth operation of university matters requires competent bodies like syndicate, academic council, selection board, finance and planning committee, advance study and research board. Bodies provide instructional leadership as well as manage day-to-day activities in universities. They also direct the educational programs and community service organizations. These bodies set educational standards, goals, rules and regulations and establish the policies and procedures to carry them out. Bodies also supervise and support faculty members, librarians, coaches, affairs and management of the property of the university. They develop academic programs, standard of teaching, monitor students, educational progress, train and motivate teachers and other staff, manage guidance and other students services, administer record keeping, planning \& development, prepare budget, handle relation with parents, prospective and current students, and the community, and performs many other duties. Bodies may handle all these functions effectively if the members are well-trained, equipped with new knowledge, management skills and decision power. 
Some of the decisions are really difficult to make because of the complexity of situation, particularly in case of several problems, which are becoming more and more complex. There is hardly any consistent and logical procedure, which the executive bodies adopt in taking decisions (Verma and Agarwal, 2003).

Presently, universities are facing the pressure of growing enrollments, curriculum modernization, shortage of funds, source allocations, appointment of staff, maintaining educational standard, offering courses as per new demands of changing era, staff development, research and scientific developments. The ultimate goal of the application of management decision-making techniques is to enable the administrators to make more rational decisions among conflict, uncertainty and unfavorable circumstances. Therefore it is intended to profound a study in the area of decision making and measures the extent to which members of university bodies adopt management techniques in making administrative and academic decisions.

\section{PURPOSE OF THE SATUDY}

The main purpose of this study is to investigate decision-making practices of the universities of Pakistan in administrative and academic matters and to observe the rate of participation by teachers, employees and students in decision making practices. It should be noted that knowledge about decision making benefited both practitioners and academicians, for practitioners, a better understanding of the nature of the gap between theory and practice could help them to evaluate alternative techniques. It would be useful for enhancing commitment, individual and collective decision-making, improving communications, stimulating more meaningful training and development, and enhancing the participation of teacher in innovative processes and change. Because of economic pressure, the demand for enhanced quality of services, and for accountability to the authorities of the system of higher education, administrators are required to cope with the complexities of changing responsibilities.

\section{METHODOLOGY}

In order to ensure adequate representation of all the areas of Pakistan, a stratified random sampling process was used to select the sample of the study, as Ary et al., (1999) were of view that in stratified sampling one first determines the strata of interest and then randomly draws a specific number of subjects from each stratum. Five strata (Sindh, Punjab, NWFP, Blochistan, and Federal) were identified from population and from each stratum onethird universities/degree awarding institutes were randomly selected. Therefore, a sample of nineteenuniversities/degree awarding institutions was selected.

The study was survey in nature; therefore questionnaires were used for data collection. Researchers developed three questionnaires called as survey of decision-making (SDM) on the basis of literature and related researches. One questionnaire was administrated to the members of university bodies, second questionnaire was administrated to the teaching staff of the university and third questionnaire was administrated to administrative officers of the university.

As the author-developed tool of research is recommended to be pilot tested to determine its efficacy and appropriateness to the subject matters (Johson and Christenson, 2000). Therefore, instruments were reviewed twice, one by a panel of experts in management and educational setting for determining its face validity, and second administered on the same kinds of respondent with a small number of sample for determine the internal consistency of the questionnaires. A split-half reliability of each questionnaire was calculated according to Spearman Brown prophecy formula and results were found ranging from 0.73 to 0.79 at $5 \%$ level confidence.

Researchers collected the data from the respondent personally and with personal contacts. Scoring was done after collection of data. Since SDM was a five point rating scale therefore the score of all positive statements ranged from 5-1 for different response categories viz. Strongly agree, Agree, Undecided, Disagree and Strongly Disagree. In order to examine the decision-making practices in the universities ANOVA was applied for determining significant difference among three means. In order to evaluate the extent of participation of teaching staff in decision-making and decision-making techniques used by university bodies a Chi Square was applied to determine whether the observed frequencies significantly differ from the expected frequencies. 


\section{RESULTS AND DISCUSSION}

Table 1

ANOVA showing the significance difference of group means Decision Making Practices

\begin{tabular}{|c|c|c|c|c|c|}
\hline Decisional areas & Source of Variance & $\begin{array}{c}\text { Sum of } \\
\text { Squares }\end{array}$ & df & Mean Square & $\mathbf{F}$ \\
\hline \multirow{2}{*}{ Based on policy matter } & Between & 6.43 & 2 & 3.21 & \multirow{2}{*}{1.59} \\
\hline & Within & 682.45 & 339 & 2.01 & \\
\hline \multirow{2}{*}{ Diplomacy } & Between & 26.73 & 2 & 13.36 & \multirow{2}{*}{$5.69^{*}$} \\
\hline & Within & 795.34 & 339 & 2.34 & \\
\hline \multirow{2}{*}{ Power delegations } & Between & 9.28 & 2 & 4.64 & \multirow{2}{*}{1.92} \\
\hline & Within & 815.90 & 339 & 2.40 & \\
\hline \multirow{2}{*}{ Investigation before decision } & Between & 9.28 & 2 & 4.64 & \multirow{2}{*}{2.04} \\
\hline & Within & 767.90 & 339 & 2.26 & \\
\hline \multirow{2}{*}{ Flexibility } & Between & 19.19 & 2 & 9.59 & \multirow{2}{*}{$4.07 *$} \\
\hline & Within & 798.06 & 339 & 2.35 & \\
\hline \multirow{2}{*}{ Information from all channels } & Between & 10.33 & 2 & 5.16 & \multirow{2}{*}{1.93} \\
\hline & Within & 904.00 & 339 & 2.66 & \\
\hline \multirow{2}{*}{ Analyze the after effects } & Between & 9.98 & 2 & 4.99 & \multirow{2}{*}{1.82} \\
\hline & Within & 926.65 & 339 & 2.73 & \\
\hline \multirow{2}{*}{ Financial problems aroused } & Between & 11.95 & 2 & 5.97 & \multirow{2}{*}{2.19} \\
\hline & Within & 921.46 & 339 & 2.71 & \\
\hline \multirow{2}{*}{ Use rules to suit themselves } & Between & 20.79 & 2 & 10.39 & \multirow{2}{*}{$4.09^{*}$} \\
\hline & Within & 860.37 & 339 & 2.53 & \\
\hline \multirow{2}{*}{ Ignore favoritism } & Between & 6.15 & 2 & 3.07 & \multirow{2}{*}{1.92} \\
\hline & Within & 875.31 & 339 & 2.58 & \\
\hline \multirow{2}{*}{ Implement decisions fast } & Between & 20.22 & 2 & 10.11 & \multirow{2}{*}{$4.38^{*}$} \\
\hline & Within & 782.08 & 339 & 2.30 & \\
\hline \multirow{2}{*}{ Systematic thinking and Planning } & Between & 8.44 & 2 & 4.22 & \multirow{2}{*}{1.77} \\
\hline & Within & 805.71 & 339 & 2.37 & \\
\hline
\end{tabular}

* Significant table value of $\mathrm{F}$ at 0.05 level $=2.99$

A perusal of Table 1 shows that decisions by university bodies are not based on policy matter of the university as the calculated value of $\mathrm{F}$ was found to be 1.59 , which is less than table value. University bodies use diplomacy in their decision-making $(\mathrm{F}=5.69>$ table value at 0.05 level $)$. University bodies do not delegate the powers for better decisions $(\mathrm{F}=5.69<$ table value at 0.05 level). This finding supports the study conducted by Matthai et al., (1992). University bodies do not investigate all the matters before taking any decision (value of $F$ was found to be 2.04, which is less than table value at 0.05 level). The calculated value of $F=4.07$, which is greater than table value at 0.05 level, which supports university bodies show flexibility in decisions. ANOVA showing the significance difference of group means on getting information from all channels demonstrates that the calculated value of $\mathrm{F}$ was found to be 1.93, which is less than table value at 0.05 level, which conveys that in decision-making, university bodies do not get information from all channels. University bodies do not analyze the after effects of decision making $(\mathrm{F}=1.82<$ table value at 0.05 level $)$, and also that their decisions do not create financial problems to university ( $\mathrm{F}=2.19$ <table value at 0.05 level). The calculated value of $\mathrm{F}$ was found to be 1.92 , which is less than table value at 0.05 level, therefore, it concludes that university bodies do not ignore favoritism in their decisionmaking. For the matter that university bodies implement their decisions fast $(\mathrm{F}=4.38>$ table value at 0.05 level $)$. Further it was found that university bodies do not make decisions with systematic thinking and planning as the calculated value of $\mathrm{F}$ was found to be 1.77 , which is less than table value at 0.05 level. 
Table 2

Chi Square showing the significance difference of Participation by teachers, employees and students in decision making

\begin{tabular}{lcccc}
\hline Participation & N & Mean & df & $\chi^{2}$ \\
\hline Teacher & 114 & 2.78 & 4 & $8.36^{*}$ \\
Employees & 114 & 3.18 & 4 & $7.40^{*}$ \\
Students & 114 & 2.78 & 4 & $5.38^{*}$ \\
\hline
\end{tabular}

* Not significant $\quad \chi^{2}$ at 0.05 level $=9.488$

The data of Table 2 indicates that the value of $\chi^{2}$ was found to be 8.36 for teaches, 7.40 for employees and 5.38 for students which are less than the table value at 0.05 level, which demonstrate that teachers, employees and students were ignored to participate in Decision Making Practices.

\section{DISCUSSION}

Study of decision-making initiatives cannot be isolated from day-to-day institutional operations; decisions are being continuously made in university system at various levels. These decisions deal with various dimensions of operation of the university system and subsystem. While the apex level bodies make decisions that affect the total university system, in this perspective Valero (1997) says these bodies adopt various policies and strategies for running and promoting organizational health of university system. Over all decision making practices in universities of Pakistan are influenced by certain variables like ignoring the rule of law, diplomacy, favoritism, interpreting the situation without having much information and without copulation. In a decision making study Matthai et al., (1992) found similar variables that effect decision making strategies in university system, therefore findings were not surprising.

Unfortunately, in Pakistan there is a long tradition of making decisions based on factors other than merit, that's why the decision-making practices were found to be unsatisfactory. Of course, changing this culture and deteriorated conditions takes time, but effective steps need to be taken. Moreover, certain measures and administrative reforms be introduced to bring about a better change. Gore (1977) presented a useful framework for an analysis of decision-making in higher educational institutions. He analyzed whether decisions are made at individual level or at a group level. He found that decisions were made at apex level without participation of academic staff. He recommended and reported that participation in decision-making becomes an important dimension, as it is believed that people at lower levels in the hierarchy are more familiar with the field problems. He pointed out that decentralization in decision-making increases the need for coordination at the higher levels.

In the present study the participation of teaching staff in decision-making process appeared to be considerably ignored. And, the findings related to participation of teaching staff in decision-making process absolutely matched the findings presented by Gore (1977). Researchers agreed that the facilitation of greater involvement of teachers in university administrative and academic affairs came out as a serious administrative and leadership problem. The general absence of culture of regular dialogue and joint forums in our universities is manifested in rising cases of unrest. University problems increase, if there is lack of mutual communication between the administration and university staff.

Matthai et al., (1992) described that the university has its apex levels bodies such as syndicate, academic council, faculties and board of studies, planning committees to take decisions. It has the administrators like Vice Chancellor, registrar, directors, deans and head of the departments. He mentions that in decisions such as programme selection, faculty selection, planning and allocating budgets and formulating the academic policies, there should be participation of all the members of statutory bodies. But in Pakistan it appeared that the structure of universities did not offer a great degree of autonomy to members to make decisions.

Researchers found that main decision maker in universities are Vice-Chancellor but the objective criteria did not found for his appointment. Actually, Vice-chancellor's post is a political post because of its power structure and Lakha (2002) mentioned that the senate and syndicate had been left ineffective under the current complex and 
intertwined system, whereas the Vice-chancellor is left with indecipherable executive powers or is in a continuous conflict with the syndicate and the senate.

The researchers felt that decision-making and consensus in Pakistan are done in a black hole; there is no need to apply any technique in order to choose best possible solution. The researchers also understand that in Pakistan decision making techniques may not be applied because of two key challenges. The first one is the trade unionization of teachers, employees, students and their parties. University administrators have to deal with a whole host of trade unions that often employ strong-arm tactics in dealing with the university leadership. While representation itself is a desirable thing, the undue politicization of these processes and the deep involvement of political parties in decision making have resulted in a degeneration of the dialogue. This process distracts from the possibility of the implementation of decision-making techniques. The second is lack of awareness of decisionmaking techniques; more broadly in the management of universities there is non-existence of training for university administrators and Vice-chancellors in the area of decision-making. Administrators usually do not have any management and decision-making expertise prior to their jobs and learning, if any, is expected to happen during the process. This leads directly to a solidification of the status quo and to the lack of fresh ideas in university management and decision making process.

\section{CONCLUSION AND RECOMMENDATIONS}

Decision-making practices in universities were found unsatisfactory due to centralization of powers and exploitation of rules and regulations. Decisions are not made on the basis of specific technique because of bureaucratic culture and political interference of ruling party. There is no set criteria for the appointment of the Vice-Chancellors in the universities, therefore it has become a political post. Most of the persons, who were appointed as Vice-Chancellor, had often no sound academic background. Although, there is effective participation of teachers in evaluating the quality of publications, research, and promoting advanced studies in universities. But teachers were not authorized and involved properly in decision-making especially, in departmental matters like instructional policies, allocating budgets, determining goals and work plans.

The researchers regarded this study as the foundation stone in the field of decision-making in universities. A more detailed investigation is needed about types of challenges faced by university administrators, and the information, which is required for their decisions. Researchers has not examined and compared the relationship of decision-making abilities and techniques between academic and non-academic members of the university; therefore a study can be conducted in this perspective. In this study researchers have got limited sample, therefore the findings of this study should be tested in a larger sample that includes more institutions of higher education. Moreover, it would be interesting to design a more detailed investigation only in management skills of academic administrators at the operative level, especially the department chairs, in the institutions of higher education at the national level.

\section{AUTHOR INFORMATION}

Anwar, M. Nadeem is working as Assistant Professor in Department of Education, University of Sargodha, Pakistan. He did M.Phil. in Education from Alllama Iqbal Open University, Islamabad, Pakistan and Ph.D. in Education from University Institute of Education and Research, UAAR. The main areas of his interest are distance education, continuing education, and teacher education. His teaching and research areas are Management, Educational Leadership and Organizational Behavior.

Dr. Muhammad Nadeem Anwar

Assistant Professor,

Department of Education, University of Sargodha, PAKISTAN

E-mail: nadeem_phd@yahoo.com

Yousuf, M. Imran is working as Assistant Professor in Division of Continuing Education, Pir Mehr Ali Shah Arid Agriculture University, Rawalpindi, Pakistan. He did M.Phil. in Education from Alllama Iqbal Open University, 
Islamabad, Pakistan and Ph.D. in Education from University Institute of Education and Research, UAAR. The main areas of his interest are distance education, continuing education and teacher education

Dr. Muhammad Imran Yousuf

Assistant Professor,

Division of Continuing Education,

Pir Mehr Ali Shah Arid Agriculture University

Rawalpindi, PAKISTAN

E mail: dr.imran@uaar.edu.pk

Sarwar, M. is working as Assistant Professor in Education, University of Sargodha, Pakistan. He did M.Phil. in Education from Alllama Iqbal Open University, Islamabad, Pakistan and Ph.D. in Education from University Institute of Education and Research, UAAR. The main areas of his interest are distance education, teacher education and educational assessment.

Dr. Muhammad Sarwar

Assistant Professor,

Department of Education

University of Sargodha, PAKISTAN

E-mail: drmiansarwar@yahoo.com

\section{REFERENCES}

1. Ary, D., Jacobs K. and Razaviech, A. (1990). Introduction to Research in Education. Harcourt Brace Jovanovich College, Fort Worth TX.

2. Choudhury, N.R. (2001). Management in Education. A.P.H. Publishing Corporation, New Delhi.

3. Foxley, C. (1980). Determinants of Managerial Effectiveness. New Directions for Student Services. 9: 1-10.

4. $\quad$ Gore, M.S. (1977). Decision Making: A Framework for Analysis. In Matthai, R. J., U. Pareek and T. V. Rao (Eds) Institution Building in Education and Research. All India Management Association, New Delhi.

5. Griffin, R.W. (2000). Griffin's Fundamental of Management: Core Concept and Application. Houghton Mifflin Company, Boston.

6. Jennings, D. and Wattam, S. (1994). Decision Making: An Integrated Approach. Pitman Publishing, New York.

7. Johnson, B. and Christenson, L. (2000). Educational Research: Quantitative and Qualitative Approaches. Allyn and Bacon, Boston.

8. Lakha, S.K. (2002). Higher Education in Pakistan: Towards reforms Agenda. Draft report.

9. Lunenburg, F. and Ornstein, A. C. (1990). Educational Administration. Wadsworth Publishing Company, Washington.

10. Marvin, P. (1981). Multiplying Management Effectives. Taraporevala Publishing Industries, New York.

11. Massie, J.L. (1992). Essentials of Management. Prentice-Hall of India Pvt. Ltd., New Delhi.

12. Matthai, R.J., Pareek, U. and Rao, T.V. (1992). Management Process in Universities. Oxford \& IBH Publishing Company Private Ltd., New Delhi.

13. McGrath, E.H. (1986). Basic Managerial Skills for All. Prentice-Hall of India Private Ltd., New Delhi.

14. Mintzberg, H. (1973). The Nature of Managerial Work. Harper \& Row, NY.

15. Mohanty, J. (1998). Educational Administration Supervision and School Management. Oxford \& IBH Publishing Co. Pvt. Ltd., New Delhi.

16. Rourke, F.E. and. Brook, G.E. (1966). The Managerial Revolution in Higher Education. The Johns Hopkins Press, New York.

17. Simon, H. (1976). Administrative Behaviour. Free Press, New York.

18. Valero, C.A. (1997). Applications of qualitative and quantitative techniques of management in administrative/academic Decision-making in institutions of higher education in Virginia. Ph.D. Dissertation. State University, Virginia. 
19. Verma, M.M. and Agarwal, K. (2003). Quantitative Techniques. Kings Books Education Publishers, New Delhi.

20. Vesey, L.R. (1965). The emergence of the American University. The University of Chicago Press, Chicago.

21. Weber, M. (1983). Max Weber on Capitalism, Bureaucracy, and Society. Allen \& Unwin Publishers, Boston. 